\title{
Research on Control Method of Single-Phase Inverter Power Based on SVPWM
}

\author{
Jianhui Zhang ${ }^{1, \text { a }}$ \\ ${ }^{1}$ School of Electrical and Electronic Engineering, East China Jiaotong University, Nanchang, Jiangxi, \\ 330013, China \\ azhang-jh@163.com
}

Keywords: inverter, control method, space-vector pulse width modulation

\begin{abstract}
The paper presents a new control method based on voltage space-vector pulse width modulation, which designed by aiming at the defects in traditional control methods of single-phase inverter power. The system models are obtained by using simulation software Simulink of Matlab. The results are achieved through theory analysis and simulation experiment, which prove the feasibility and advantage of the new control method.
\end{abstract}

\section{Introduction}

The common control method of inverter power includes SPWM, SHEPWM and SVPWM [1]. The SPWM can realize to control the voltage easily, and the control linearity is good, but the voltage utilization rate is low. Moreover, the output maximum value of fundamental voltage amplitude is half of the input DC voltage by using a general method of linear modulation. At the same time, the switching loss is larger under the same switching frequency. The SHEPWM can eliminate the selective harmonic only, which can't improve the voltage waveform fundamentally. On the other hand, the control method of SHEPWM is complex in calculation and large in computing capacity, which not suitable for real time control. The SVPWM is presented by Japanese scholar in the mid-1980s, which aiming at the speed regulation of AC motor, and developed through the thought of magnetic flux control. The SVPWM have these advantages that the physical concept is clear, the voltage utilization rate is high, the low harmonic content is less, the switching loss is small, and can achieve digital control easily because of it's algorithm is simple [2]. The control method of SVPWM is widely used in all kinds of three-phase inverter powers, but it is not often seen in single-phase inverter power. The paper studies the basic principle of three-phase SVPWM technology, and transplants the various research results of SVPWM in three-phase inverter power into the single-phase SVPWM technology, which can obtain better control effect for single-phase inverter circuit.

\section{Analysis on Voltage Space-Vector of Single Inverter Power}

The circuit of single-phase inverter power is a full bridge inverter circuit ordinarily, as shown in Fig.1 [3]. The switch elements of the up and down bridge arms cannot be conducted simultaneously at any moment when the inverter power working, the switch states of the up and down bridge arms are complementary without considering the stagnant wake. Because of this, we can describe the working state of the inverter by using the switch state of the power devices on the two up bridge arms. The ideal two position switch $\mathrm{K}_{\mathrm{a}}$ and $\mathrm{K}_{\mathrm{b}}$ represents the switch state of the power devices in order to study on calculation easily. The circuit model is shown in Fig.1.

The each switch has two states of ' 1 ' and ' 0 ' in Fig.1, ' 1 ' shows the switch contact the upper contactor, that is, the upper bridge arm IGBT conduction. On the other hand, ' 0 ' shows the switch contact the lower contactor, that is, the lower bridge arm IGBT conduction. Thus, it has four states by the combination of $\mathrm{K}_{\mathrm{a}}$ and $\mathrm{K}_{\mathrm{b}}$. The output voltage under the four switch states can be marked as $v_{0}, v_{1}, v_{2}$ and $v_{3}$ by the method of natural binary code. The table 1 describes the corresponding relationship of the power device switching state and output voltage vector. 


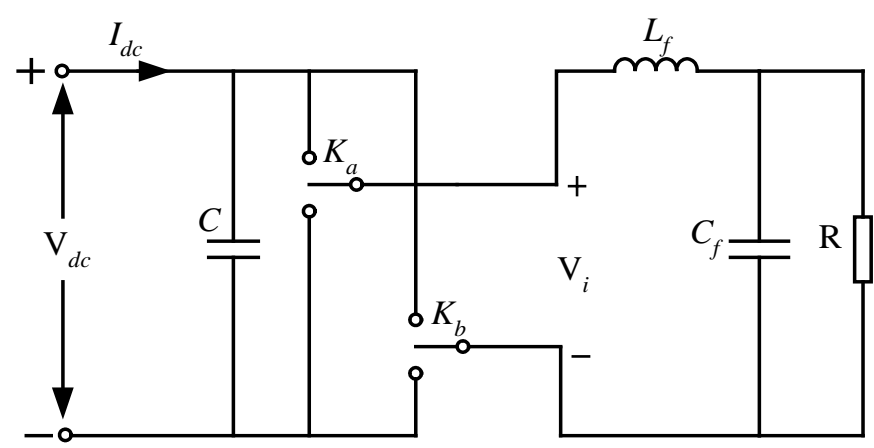

Fig. 1: Circuit of single-phase full bridge inverter
Table 1: Corresponding of the power device switching state and output voltage vector

\begin{tabular}{c|c|c|c}
\hline $\mathrm{K}_{\mathrm{a}}$ & $\mathrm{K}_{\mathrm{b}}$ & $\mathrm{V}_{\mathrm{i}}$ & $\left.\begin{array}{c}v_{\mathrm{k}} \\
(\mathrm{k}=0 \sim 3\end{array}\right)$ \\
\hline 0 & 0 & 0 & $v_{0}$ \\
\hline 0 & 1 & $-\mathrm{V}_{\mathrm{dc}}$ & $v_{1}$ \\
\hline 1 & 0 & $\mathrm{~V}_{\mathrm{dc}}$ & $v_{2}$ \\
\hline 1 & 1 & 0 & $v_{3}$ \\
\hline
\end{tabular}

The voltage vector $v=\left[V_{\mathrm{ab}}\right]$ forms 4 discrete voltage space vectors in one-dimensional space, as shown in Fig.2, we can see the vector $v_{1}$ and $v_{2}$ on the $x$ axis, the vector $v_{0}$ and $v_{3}$ on the original point.

We can analyse the single-phase sinusoidal power supply by the same method, supposing

$$
u=U_{m} \sin \omega t
$$

Thus, Fig.3 describes the single-phase power supply vector $\boldsymbol{u}=[u]$ in one-dimensional space, the modulus of $u$ changes by the sine law follow the time $t$ [4].

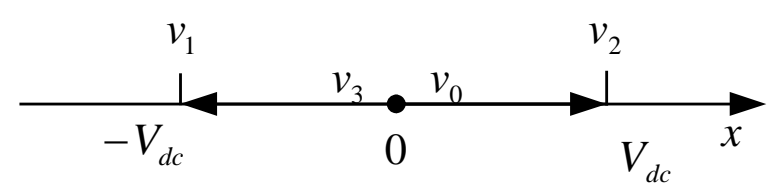

Fig. 2: Space-vector of inverter output voltage

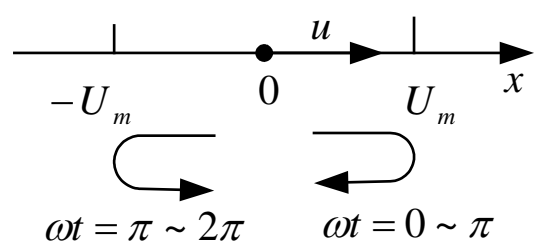

Fig. 3: Space-vector of sinusoidal voltage

Obviously, the inverter output state transforms from $v_{0}, v_{1}, v_{2}$ and $v_{3}$. If the modulus of $u$ over $V_{d c}$, then can't synthetise the equivalent vector of sinusoidal power supply. Because of this, we can define modulation ratio $\mathrm{M}$, as shown in Eq. 2.

$$
M=\frac{U_{m}}{V_{d c}} \leq 1
$$

\section{Modulation Algorithm of Single-Phase Voltage Space Vector}

Analysing the above 4 voltage space vetor, we discover that the inverter output voltage is zero by corresponding to $v_{0}$ and $v_{3}$, which can be marked as zero vector. On the other hand, $v_{1}$ and $v_{2}$ can be marked as non zero vector. The zero vector can't impact the synthetised sine wave amplitude, but we can distribute the zero vector working time reasonably to reduce the switching times of the switching device, furthermore, which can reduce the switching loss and the harmonic [5].

In a carrier cycle, we can select non zero vector according to $v_{i \_a v}$. If $v_{i \_a v} \in\left[-U_{m}, 0\right]$, we select the vector $v_{1}$, and if $v_{i_{\_} a v} \in\left[0, U_{m}\right]$, we select the vector $v_{2}$. The working time of non zero vector can be obtained by Eq. 3, which marked as $T_{c}$.

$$
T_{c}=\frac{v_{i_{-} a v}}{V_{d c}} T_{\text {period }}
$$

Where $V_{d c}$ is the DC bus voltage, $T_{\text {period }}$ is the PWM carrier cycle. The working time of zero vector can be obtained by Eq.4, which marked as $T_{0}$.

$$
T_{0}=T_{\text {period }}-T_{c}
$$


Next, we select zero vector. There are two different modulating modes according to the selecting of zero vector and the working time distribution of non zero vector. Fig. 4 shows the modulating mode I , which distributes the two zero vectors averagely in a PWM period, the working time of each zero vector is $T_{0} / 2$, and then distributes zero vector, non zero vector by the principle of switch state changes at least. Under the modulating mode I , each switch element will operate twice in a PWM period. Fig.5 shows the modulating mode II, which fixed selects $v_{0}$ as the zero vector. Under the modulating mode II, there is one bridge arm not working in a PWM period. The total switch times is reduced a half compared with the modulating mode I .

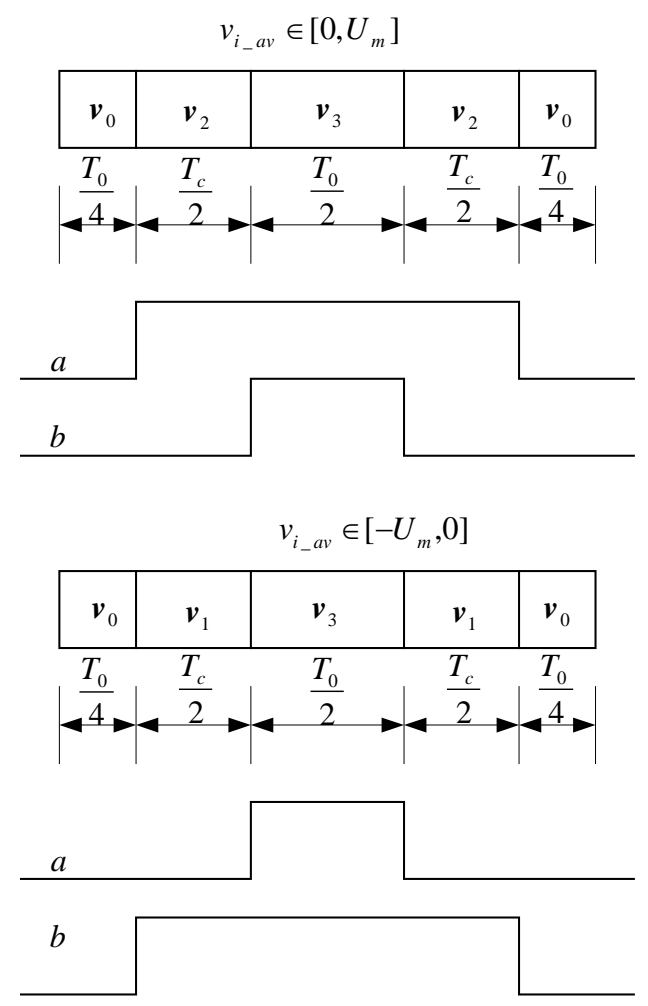

Fig. 4: Modulating mode I
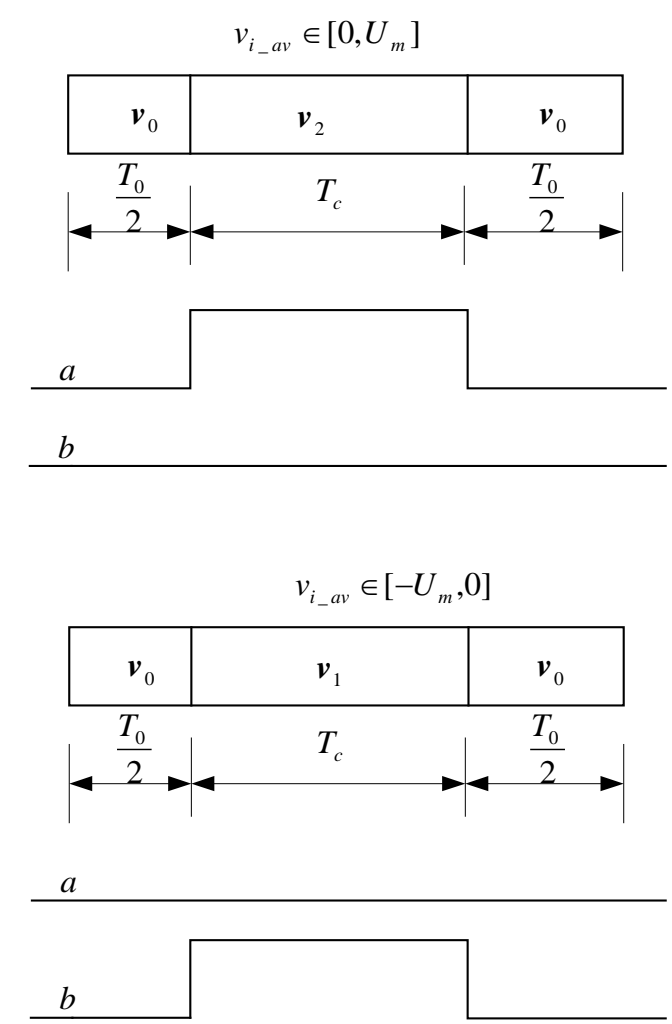

Fig. 5: Modulating mode II

\section{Simulation Experiment}

We establish the simulation model of single-phase inverter by Matlab/Simulink software based on the above analysis. The simulation parameter settings: DC input voltage $V_{d c}=400 \mathrm{~V}$, the amplitude of referenced sinusoidal voltage $V_{-}$ref $=220 \mathrm{~V}$, PWM carrier frequency $f=20 \mathrm{kHz}$, filter inductor $L_{f}$ $=2 \mathrm{mH}$, filter capacitor $C_{f}=10 \mathrm{uF}$, and the load resistance $R=20 \Omega$.

Simulation Analysis of Two Modulating Modes. The harmonic distribution of inverter output voltage is different by using different SVPWM modulating mode. Based on the above two modulating modes, we can achieve FFT analysis of the output signals by Matlab/Powergui module.

From the Fig.6, we can see the first harmonic occurs at the frequency of $40 \mathrm{kHz}$ by using modulating mode I . On the other hand, in the Fig.7, the first harmonic occurs at the frequency of 20 $\mathrm{kHz}$ by using modulating mode II. According to the simulation result, we discover the harmonic content of output voltage is less by using modulating mode I . Because of this, we use the modulating mode I to achieve single-phase SVPWM control.

Simulation Result of Load Voltage. To the single-phase inverter power, the worst load is nonlinear load. We use a single-phase bridge rectifier as the nonlinear load in emulating. The simulation wave is shown in Fig.8, the load waveform is very ideal, and the content of THD is 3.5\% similarly. Because the load changes frequently in actual using, it is necessary to test the dynamic change of the inverter output when the load changes. The output voltage, current simulation wave of dynamic load is shown in Fig.9. 

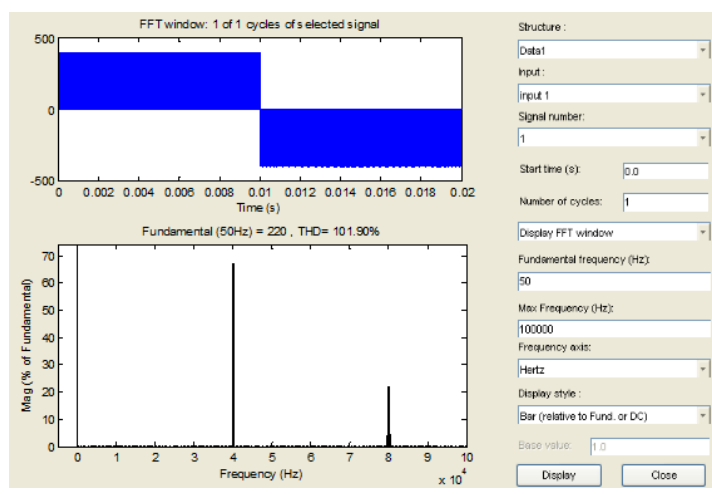

Fig. 6: FFT of output voltage by mode I

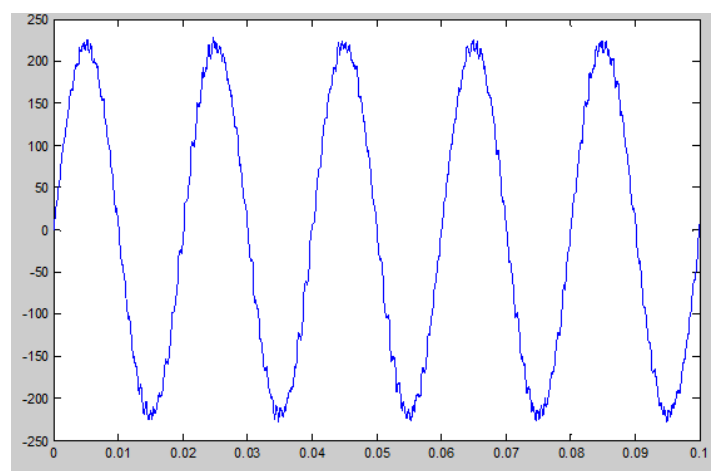

Fig. 8: Output voltage wave of nonlinear load

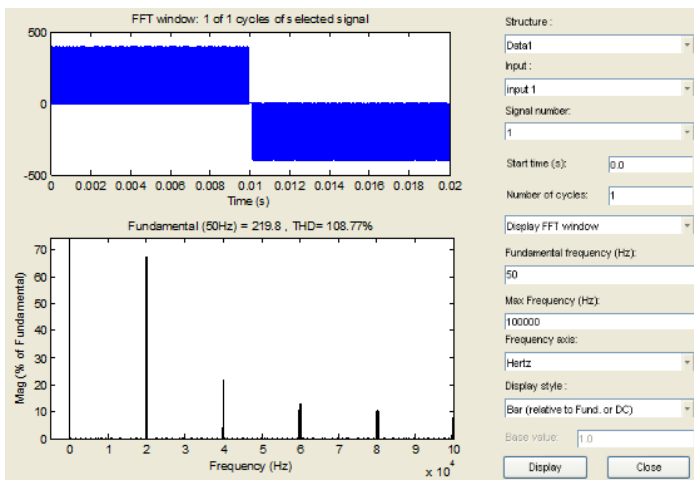

Fig. 7: FFT of output voltage by mode II

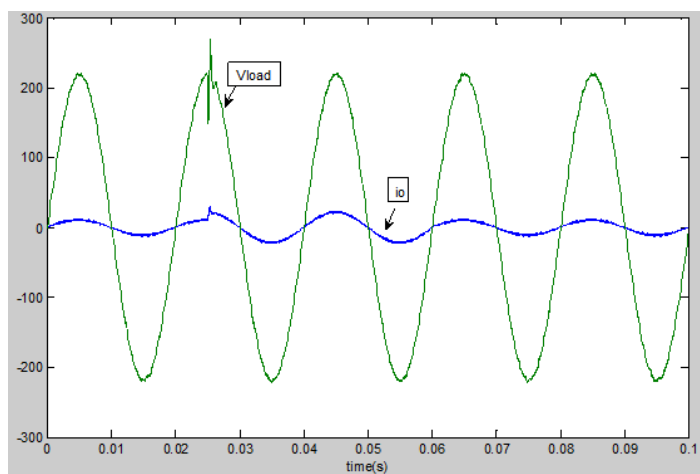

Fig. 9: Output wave of dynamic load

\section{Summary}

The results of simulation experiment shows that the SVPWM technology is more flexible, and can achieve digital control easily because of it's algorithm is simple. Furthermore, the presented modulating mode is good, and the output voltage wave has good quality with the linear load and nonlinear load, it has obvious advantages compared with other control method.

\section{Acknowledgements}

The paper supported by the science foundation of East China Jiaotong University (14DQ05)、 (11DQ07).

\section{References}

[1] P.G. Song: Research on Power Converter and Optimal Controller of Variable Speed Wind Power Generation System (Ph.D., Southwest Jiaotong University, China 2006), p.15.

[2] L.Q. Yi, Y.X. Dai: Transactions of China Electrotechnical Society, Vol. 22 (2007) No.9, p.112.

[3] J. Chen: Power Electronics (Higher Education Press, China 2002).

[4] W.P. Zhou, Z.G. Wu: Advanced Technology of Electrical Engineering and Energy, Vol. 24 (2005) No.2, p.28.

[5] N.G. Hong: Modeling and Simulation of Control System of Power Electronics and Motors (China Machine Press, China 2011). 